\title{
Demands Along The Supply Chain
}

Nick T. Thomopoulos, Illinois Institute of Technology, USA

\begin{abstract}
This paper describes how the monthly demands vary at the locations along the supply chain, coming from the customers to a dealer onto a distribution center and finally to a supplier. The mean, standard deviation and coefficient of variation are measured for each of the locations. The results indicate when the demands tend to be normally distributed and when non-normal.
\end{abstract}

Keywords: Supply Chain; Monthly Demands; Customers; Dealers; Distribution Centers; Suppliers; Normally Distributed; Lumpy Months-in-Buy and Coefficient-of-Variation

\section{INTRODUCTION}

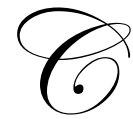

onsider a dealer that carries inventory on parts to meet the oncoming customer demands. This paper assumes that the monthly demands from the customers are horizontal (no trend or seasonal pattern) and also that the monthly demands at a dealer are shaped like a Poisson probability distribution. The dealer replenishes the stock on the part from a distribution center (DC) and the DC is replenished from a supplier. The replenishment quantity, Q, at a location depends mostly on the forecast of demands and the cost per unit. For convenience, the replenishment order quantity can be stated in month-in-buy (mib) terms where $Q=\operatorname{mib} \times \mu$ and $\mu$ is the average of the monthly demand forecast at the location. When mib is 1.0, Q is a one-month supply and when mib is 2.0, Q is a two-month supply, and so forth. The aggregate flow of replenishments from all the dealers is the demand at the DCs; and the flow of replenishments from the DCs is the demand at the supplier. This paper shows how the demands along the supply chain, at the dealer, DC and the supplier are related.

The results apply for the supply chain on a part (or product) that has a single supplier, many dealers and one or more distribution centers. This arrangement is common, for example, when the items in stock are service parts that are needed for the repair and maintenance of finished goods items or are consumer products that are sold at a store to meet individual customer needs.

\section{NOTATION}

To clarify the discussion to follow, the notation used in this paper is summarized below:

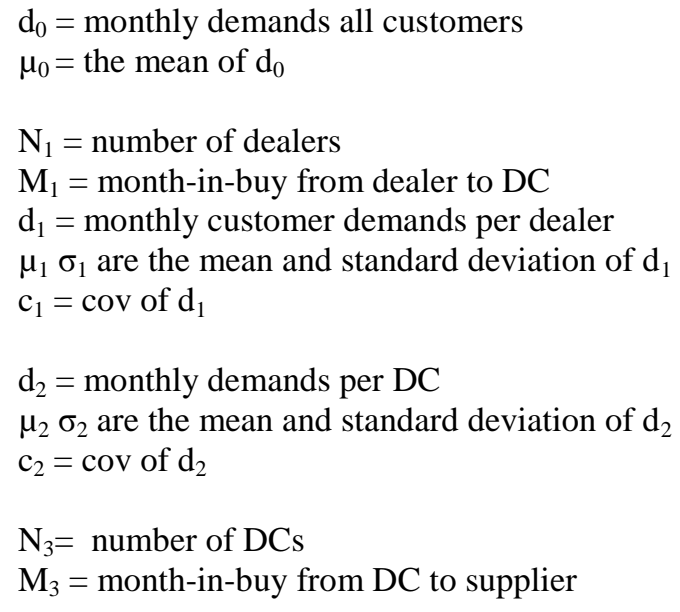


$\mathrm{d}_{3}=$ monthly demands all DCs

$\mu_{3} \sigma_{3}$ are the mean and standard deviation of $d_{3}$

$\mathrm{c}_{3}=\operatorname{cov}$ of $\mathrm{d}_{3}$

$\mathrm{d}_{4}=$ monthly demands to supplier

$\mu_{4} \sigma_{4}$ are the mean and standard deviation of $d_{4}$

$\mathrm{c}_{4}=\operatorname{cov}$ of $\mathrm{d}_{4}$

\section{MONTHLY DEMANDS FOR ALL CUSTOMERS}

In this study, we assign $\mathrm{d}_{0}$ as the monthly demand for an item from all customers across all dealers and further denote $\mu_{0}$ as the corresponding average monthly demand of $\mathrm{d}_{0}$. This paper gives examples where the aggregate averages of the customer demands are $\mu_{0}=10,100$ and 1000 .

\section{MONTHLY DEMANDS FOR AN AVERAGE DEALER}

The demand for an average dealer is denoted as $d_{1}$, and when the number of dealers is $N_{1}$, the mean monthly demand for an average dealer $\left(\mu_{1}\right)$ becomes $\mu_{1}=\mu_{0} / \mathrm{N}_{1}$. Because the national demands for an item are spread over many dealers, the monthly demands for each stock-keeping-unit (SKU) at an individual dealer are typically small. For this reason, the Poisson distribution is assumed as the distribution for the monthly demands (from the customers to an individual dealer). The Poisson is also ideal for analysis since it is a one parameter distribution since the mean and variance are equal. Thereby, we assume the monthly demands coming to a dealer from its customers is Poisson with an average of $\mu_{1}$ and has a standard deviation of $\sigma_{1}=\sqrt{\mu_{1}}$. Recall the coefficient of variation (cov) of a random variable is defined as the ratio of the standard deviation over the average, so in this situation, the coefficient of variation becomes $\operatorname{cov}_{1}=\sigma_{1} \mu_{1}$. Table 1 lists values $\mu_{1}, \sigma_{1}$ and $\operatorname{cov}_{1}$ as the average monthly demands range from 1 to 1,000 . Note how $\operatorname{cov}_{1}$ is largest (1.00) when $\mu_{1}=1$ and becomes increasingly smaller as $\mu_{1}$ rises. In the table, the cov extremes are 1.00 on the high end and 0.03 on the low end. Further note that when the demands are all positive and normally distributed, the cov attains a value is 0.33 or less. This is because (with all demands positive) the mean is at least three standard deviations larger than zero. On the other extreme, when the cov is one, the monthly demands are distributed as an exponential distribution since for this distribution, the standard deviation is the same as the mean.

So in essence, the monthly demand for an average dealer goes up or down in the same direction as the monthly demands of all customers. As Table 1 shows, when the average monthly demands are low at the dealer, the cov increases, and thereby the distributions of monthly demands are of the lumpy type and are shaped more like an exponential distribution. As the average monthly demands increase at an average dealer, the cov falls and the distributions of monthly demands are more like the normal distributions.

Table 1: Monthly Demand Statistics for an Average Dealer

\begin{tabular}{lll}
\hline $\boldsymbol{\mu}_{\mathbf{1}}$ & $\boldsymbol{\sigma}_{\mathbf{1}}$ & $\mathbf{c o v}_{\mathbf{1}}$ \\
\hline 1 & 1.00 & 1.00 \\
5 & 2.24 & 0.45 \\
10 & 3.16 & 0.32 \\
50 & 7.07 & 0.14 \\
100 & 10.00 & 0.10 \\
500 & 22.36 & 0.04 \\
1000 & 31.62 & 0.03 \\
\hline
\end{tabular}

\section{MONTHLY DEMANDS FOR AN AVERAGE DC}

The monthly demand for an average distribution center (DC) is here denoted as $\mathrm{d}_{2}$. The associated mean monthly demand is $\mu_{2}$ and corresponding standard deviation is $\sigma_{2}$. Also, the coefficient of variation is $\operatorname{cov}_{2}=\sigma_{2} / \mu_{2}$. We compute the measures $\left(\mu_{2}, \sigma_{2}, \operatorname{cov}_{2}\right)$ for an average DC in the analysis given below. 


\section{ANALYSIS}

When the dealer needs replenishment stock, it buys from its assigned distribution center (DC). The buy quantities (also called order quantities or purchase quantities) are in lot sizes that are economical for them. Suppose the lot size is q and this quantity is sufficient for the forecast of demands over the next mib months. In this analysis, $\mathrm{mib}=$ months-in-buy and represents the buy amount of replenishment stock in monthly requirements. Of interest here is to measure the mean and variance for the average monthly replenishment quantities from the dealer to the DC. For notation, $\mathrm{E}(\mathrm{q})=$ expected replenishment quantity per month and $\mathrm{V}(\mathrm{q})$ is the associated variance.

Consider the general situation when the months-in-buy, mib, is an integer of $m=1,2,3, \ldots$ Suppose the dealer demands for the most recent $\mathrm{m}$ months are $\mathrm{d}(1), \ldots, \mathrm{d}(\mathrm{m})$. Also assume the stock at the dealer is adequate at the first month $(\mathrm{t}=0)$ and the dealer first needs replenishment stock at month $\mathrm{t}=\mathrm{m}$, for a quantity size that covers the next $\mathrm{m}$ month requirements. So the replenishment quantity from the dealer to the $\mathrm{DC}$ will be $\mathrm{q}(\mathrm{t})=0$ for months $\mathrm{t}=1$ to $\mathrm{m}-1$ and will be approximately $\mathrm{q}(\mathrm{m})=(\mathrm{d}(1)+\ldots+\mathrm{d}(\mathrm{m}))$ at the end of month $\mathrm{m}$. Since mib $=\mathrm{m}$, this pattern will repeat as the months move along. Of interest now is to determine the expected value and variance of the monthly replenishment quantities, $q(\mathrm{t})$. Note $(\mathrm{m}-1)$ of the quantities are zero and one quantity is a m-month supply. The expected value of $q$ is:

$$
\begin{aligned}
\mathrm{E}(\mathrm{q}) & =((\mathrm{m}-1) / \mathrm{m}) \times 0+1 / \mathrm{m} \times \mathrm{E}(\mathrm{d}(1)+\ldots+\mathrm{d}(\mathrm{m})) \\
& =1 / \mathrm{m} \times \mathrm{m} \mathrm{E}(\mathrm{d}) \\
& =\mathrm{E}(\mathrm{d}) .
\end{aligned}
$$

In a similar way, the expected value of $\mathrm{q}^{2}$ becomes

$$
\begin{aligned}
\mathrm{E}\left(\mathrm{q}^{2}\right) & =1 / \mathrm{mE}\left[(\mathrm{d}(1)+\ldots+\mathrm{d}(\mathrm{m}))^{2}\right] \\
& =1 / \mathrm{m}\left[\mathrm{mE}\left(\mathrm{d}^{2}\right)+\mathrm{m}(\mathrm{m}-1) \mathrm{E}(\mathrm{d})^{2}\right] \\
& =\mathrm{E}\left(\mathrm{d}^{2}\right)+(\mathrm{m}-1) \mathrm{E}(\mathrm{d})^{2} \\
& =\mathrm{V}(\mathrm{d})+\mathrm{E}(\mathrm{d})^{2}+(\mathrm{m}-1) \mathrm{E}(\mathrm{d})^{2} \\
& =\mathrm{V}(\mathrm{d})+\mathrm{mE}(\mathrm{d})^{2} .
\end{aligned}
$$

Finally, the variance of $\mathrm{q}$ becomes

$$
\begin{aligned}
\mathrm{V}(\mathrm{q}) & =\mathrm{E}\left(\mathrm{q}^{2}\right)-\mathrm{E}(\mathrm{q})^{2} \\
& =\mathrm{V}(\mathrm{d})+(\mathrm{m}-1) \mathrm{E}(\mathrm{d})^{2} .
\end{aligned}
$$

Returning to the notation for the average DC, the following substitutions are made:

$$
\begin{aligned}
& \mu_{2}=E(q) \\
& \sigma_{2}^{2}=V(q) \\
& \mu_{1}=E(d) \\
& \sigma_{1}^{2}=V(d) .
\end{aligned}
$$

The month-in-buy from the dealer to the DC is denoted as $M_{1}$. Further, $N_{1}$ is the number of dealers and $N_{3}$ is the number of DCs. The statistics for the mean monthly demands $d_{2}$ at an average DC are as below:

$$
\begin{aligned}
& \mu_{2}=\left(\mathrm{N}_{1} / \mathrm{N}_{3}\right) \mu_{1} \\
& \sigma_{2}^{2}=\left(\mathrm{N}_{1} / \mathrm{N}_{3}\right)\left(\sigma_{1}^{2}+\left[\mathrm{M}_{1}-1\right] \mu_{1}^{2}\right) \\
& \operatorname{cov}_{2}=\mathrm{c}_{2}=\sigma_{2} / \mu_{2}
\end{aligned}
$$

Table 2 shows how $\operatorname{cov}_{1}$ and $\mathrm{M}_{1}=$ mib are related to $\operatorname{cov}_{2}$ as $\operatorname{cov}_{1}$ ranges from 0.1 to 1.0 and $\mathrm{M}_{1}$ from 1 to 6 months. Recall, $\operatorname{cov}_{1}$ is a measure of the variation in demands from the customers to an average dealer and $\operatorname{cov}_{2}$ is the counterpart measure of the variation in demands from the dealer to the an average DC. Note how $\operatorname{cov}_{2}$ increases significantly as the $M_{1}$ increases beyond one month. Also note when $M_{1}$ is two or larger, $\operatorname{cov}_{2}$ increases gradually as $\operatorname{cov}_{1}$ goes from 0.1 to 1.0. In essence, when the mib $\left(\mathrm{M}_{1}\right)$ from the dealer to the DC increases above one, the demands to the DC become lumpy. 
Table 2: Values of $\operatorname{cov}_{2}$ as related to $\operatorname{cov}_{1}$ and $M_{1}$

\begin{tabular}{|c|c|c|c|c|c|c|c|c|c|c|}
\hline \multicolumn{11}{|c|}{$\operatorname{cov}_{1}$} \\
\hline $\mathbf{M}_{1}$ & .1 & .2 & .3 & .4 & .5 & .6 & .7 & .8 & .9 & 1.0 \\
\hline 1 & 0.10 & 0.20 & 0.30 & 0.40 & 0.50 & 0.60 & 0.70 & 0.80 & 0.90 & 1.00 \\
\hline 2 & 1.00 & 1.02 & 1.04 & 1.08 & 1.01 & 1.17 & 1.22 & 1.28 & 1.35 & 1.41 \\
\hline 3 & 1.42 & 1.43 & 1.45 & 1.47 & 1.50 & 1.54 & 1.58 & 1.62 & 1.68 & 1.73 \\
\hline 4 & 1.73 & 1.74 & 1.76 & 1.78 & 1.80 & 1.83 & 1.87 & 1.91 & 1.95 & 2.00 \\
\hline 5 & 2.00 & 2.01 & 2.02 & 2.04 & 2.06 & 2.09 & 2.12 & 2.15 & 2.19 & 2.24 \\
\hline 6 & 2.24 & 2.24 & 2.26 & 2.27 & 2.29 & 2.32 & 2.34 & 2.37 & 2.41 & 2.45 \\
\hline
\end{tabular}

\section{SUMMARY STATISTICS ACROSS THE SUPPLY CHAIN}

In summary, the demand statistics across the supply chain are given in Tables 3.1 and 3.2.

\section{MONTHLY DEMANDS FOR ALL DCS}

In this section, assume $\mathrm{N}_{3}$ is the number of DCs and $\mathrm{d}_{3}$ is the average demand for all DCs. Further, $\mu_{3}$ is the average monthly demand, $\sigma_{3}$ is the standard deviation, and $c_{3}$ is the coefficient of variation of $d_{3}$. So now, $\mu_{3}=$ $\mathrm{N}_{3} \times \mu_{2}, \sigma_{3}^{2}=\mathrm{N}_{3} \times \sigma_{2}^{2}$ and $\operatorname{cov}_{3}=c_{3}=\sigma_{3} / \mu_{3}$.

\section{MONTHLY DEMANDS FOR THE SUPPLIER}

The monthly demand for the supplier is here denoted as $\mathrm{d}_{4}$. In the same way, $\mu_{4}$ is the associated average monthly demand, $\sigma_{4}$ is the standard deviation, and $c_{4}$ is the coefficient of variation of $d_{4}$. In the calculations, $M_{3}$ is the month-in-buy from the DC to the supplier.

So now,

$\mu_{4}=\mu_{3}$
$\sigma_{4}{ }^{2}=\sigma_{3}^{2}+\left(M_{3}-1\right) \mu_{3}^{2}$

$\mathrm{c}_{4}=\sigma_{4} / \mu_{4}$

Table 3.1: Average Monthly Demands $(\mu)$ and cov (c) for All Customers, Per Dealer, Per DC, All DC's and Supplier when Number of Dealers is $N_{1}=100$ and Number of DC's is $N_{3}=1$

\begin{tabular}{|c|c|c|c|c|c|c|c|c|c|c|}
\hline \multirow[b]{2}{*}{$\mathbf{M}_{1}$} & \multirow[b]{2}{*}{$\mathbf{M}_{3}$} & \multirow{2}{*}{$\begin{array}{l}\text { All } \\
\mu_{0} \\
\end{array}$} & \multicolumn{2}{|c|}{ Per Dealer } & \multicolumn{2}{|c|}{ Per DC } & \multicolumn{2}{|c|}{ All DCs } & \multicolumn{2}{|c|}{ Supplier } \\
\hline & & & $\mu_{1}$ & $\mathbf{c}_{1}$ & $\mu_{2}$ & $\mathbf{c}_{2}$ & $\boldsymbol{\mu}_{3}$ & $\mathbf{c}_{3}$ & $\mu_{4}$ & $\mathbf{c}_{4}$ \\
\hline 1 & 1 & 10 & 0.1 & 3.16 & 10.0 & 0.32 & 10.0 & 0.32 & 10.0 & 0.32 \\
\hline 1 & 1 & 100 & 1.0 & 1.00 & 100.0 & 0.10 & 100.0 & 0.10 & 100.0 & 0.10 \\
\hline 1 & 1 & 1000 & 10.0 & 0.32 & 1000.0 & 0.03 & 1000.0 & 0.03 & 1000.0 & 0.03 \\
\hline 1 & 2 & 10 & 0.1 & 3.16 & 10.0 & 0.32 & 10.0 & 0.32 & 10.0 & 1.05 \\
\hline 1 & 2 & 100 & 1.0 & 1.00 & 100.0 & 0.10 & 100.0 & 0.10 & 100.0 & 1.00 \\
\hline 1 & 2 & 1000 & 10.0 & 0.32 & 1000.0 & 0.03 & 1000.0 & 0.03 & 1000.0 & 1.00 \\
\hline 2 & 1 & 10 & 0.1 & 3.16 & 10.0 & 0.33 & 10.0 & 0.33 & 10.0 & 0.33 \\
\hline 2 & 1 & 100 & 1.0 & 1.00 & 100.0 & 0.14 & 100.0 & 0.14 & 100.0 & 0.14 \\
\hline 2 & 1 & 1000 & 10.0 & 0.32 & 1000.0 & 0.10 & 1000.0 & 0.10 & 1000.0 & 0.10 \\
\hline 2 & 2 & 10 & 0.1 & 3.16 & 10.0 & 0.33 & 10.0 & 0.33 & 10.0 & 1.05 \\
\hline 2 & 2 & 100 & 1.0 & 1.00 & 100.0 & 0.14 & 100.0 & 0.14 & 100.0 & 1.01 \\
\hline 2 & 2 & 1000 & 10.0 & 0.32 & 1000.0 & 0.10 & 1000.0 & 0.10 & 1000.0 & 1.01 \\
\hline
\end{tabular}


Table 3.2: Average Monthly Demands $(\mu)$ and cov (c) for All Customers, Per Dealer, Per DC, All DC's and Supplier when Number of Dealers is $N_{1}=1000$ and Number of DC's is $N_{3}=5$

\begin{tabular}{|c|c|c|c|c|c|c|c|c|c|c|}
\hline \multirow[b]{2}{*}{$\mathbf{M}_{1}$} & \multirow[b]{2}{*}{$\mathbf{M}_{3}$} & \multirow{2}{*}{$\begin{array}{l}\text { All } \\
\mu_{0}\end{array}$} & \multicolumn{2}{|c|}{ Per Dealer } & \multicolumn{2}{|c|}{ Per DC } & \multicolumn{2}{|c|}{ All DCs } & \multicolumn{2}{|c|}{ Supplier } \\
\hline & & & $\mu_{1}$ & $\mathbf{c}_{1}$ & $\mu_{2}$ & $\mathbf{c}_{2}$ & $\mu_{3}$ & $\mathbf{c}_{3}$ & $\mu_{4}$ & $\mathbf{c}_{4}$ \\
\hline 1 & 1 & 10 & 0.0 & 10.00 & 2.0 & 0.71 & 10.0 & 0.32 & 10.0 & 0.32 \\
\hline 1 & 1 & 100 & 0.1 & 3.16 & 20.0 & 0.22 & 100.0 & 0.10 & 100.0 & 0.10 \\
\hline 1 & 1 & 1000 & 1.0 & 1.00 & 200.0 & 0.07 & 1000.0 & 0.03 & 1000.0 & 0.03 \\
\hline 1 & 2 & 10 & 0.0 & 10.00 & 2.0 & 0.71 & 10.0 & 0.32 & 10.0 & 1.05 \\
\hline 1 & 2 & 100 & 0.1 & 3.16 & 20.0 & 0.22 & 100.0 & 0.10 & 100.0 & 1.00 \\
\hline 1 & 2 & 1000 & 1.0 & 1.00 & 200.0 & 0.07 & 1000.0 & 0.03 & 1000.0 & 1.00 \\
\hline 2 & 1 & 10 & 0.0 & 10.00 & 2.0 & 0.71 & 10.0 & 0.32 & 10.0 & 0.32 \\
\hline 2 & 1 & 100 & 0.1 & 3.16 & 20.0 & 0.23 & 100.0 & 0.10 & 100.0 & 0.10 \\
\hline 2 & 1 & 1000 & 1.0 & 1.00 & 200.0 & 0.10 & 1000.0 & 0.04 & 1000.0 & 0.04 \\
\hline 2 & 2 & 10 & 0.0 & 10.00 & 2.0 & 0.71 & 10.0 & 0.32 & 10.0 & .05 \\
\hline 2 & 2 & 100 & 0.1 & 3.16 & 20.0 & 0.23 & 100.0 & 0.10 & 100.0 & 1.01 \\
\hline 2 & 2 & 1000 & 1.0 & 1.00 & 00.0 & 0.10 & 1000.0 & 0.04 & 1000.0 & 1.00 \\
\hline
\end{tabular}

\section{CONCLUSIONS}

In the typical way to control the parts inventory in a stocking location (dealer, DC), the replenishment measures (order point and order level) are computed using the desired service level, lead time and order size, with the assumption that the monthly demands follow the normal distribution as described in Brown (1962), Thomopoulos (1980), and Thomopoulos (1990).

When the monthly demands are of the lumpy type and the replenish computations are based on the normal distribution, the inventory control measures are not correct. Thomopoulos (1980) shows how to compute the safety stock (with order point and order level) when the monthly demands are not normally distributed, but instead are of the lumpy type. The truncated normal distribution is used for this purpose. In general, when the safety stock is computed by incorrectly assuming a normal distribution instead of the true lumpy distribution, the safety stock is not large enough. Hence, the actual service level for a lumpy item will not achieve the desired service level that is sought in the computations. Tables 3.1 and 3.2 show when the monthly demands tend to be normal and when they tend to be lumpy. When cov is less than 0.33 , the normal applies, and when cov is one or larger, the lumpy demands apply.

Table 3.1 depicts a supply chain of 100 dealers and one DC. This scenario is somewhat like a large grocery chain in a large metropolitan area. Note how the monthly demands at the dealer are often of the lumpy type. The table also shows how the monthly demands at the DC tend to be normally shaped and that the demands at the supplier are a mixture of normal and lumpy type, depending on the month-in-buy from the DC.

Table 3.2 gives measures of a supply chain of 1,000 dealers and five DCs. This scenario is like a service parts distribution network for an OEM that covers the entire country. The table shows that the monthly demands at a dealer are not normally distributed but are of the lumpy type. Further, the monthly demands going to the DCs tend to be normally shaped and finally, the demands going to the supplier (from the DC) are of the lumpy type when the dealer replenishment quantities are for two or more months of supply.

\section{SUMMARY}

This paper shows how the demand flows from the customers to the dealers to the DCs and to the supplier. The demand measures are the average monthly demand, the standard deviation and the coefficient of variation. The tables show how the shape of the monthly demands can range from normal to exponential and beyond. Recall when $\operatorname{cov} \leq 0.33$, the monthly demands could be shaped like a normal distribution and when cov $\geq 1.00$, the monthly 
demands are the lumpy type.

AUTHOR INFORMATION

Nick T. Thomopoulos is a professor at the Stuart School of Business, Illinois Institute of Technology. Nick has degrees in Business, Mathematics and Industrial Engineering. He is the author of three books: Assembly Line Systems, Hayden Books, 1973, Applied Forecasting Methods, Prentice Hall, 1980 and Strategic Inventory Management and Planning, Hitchcock Publishing Co., 1990.

\section{REFERENCES}

1. Brown, Robert, G., (1962), Smoothing, Forecasting and Prediction of Discrete Time Series, Prentice Hall, Inc.

2. $\quad$ Thomopoulos, Nick T., (1980), Applied Forecasting Methods, Prentice Hall, Inc.

3. Thomopoulos, Nick T., (1990), Strategic Inventory Management and Planning, Hitchcok Publishing Co. 